Bulletin of the AAS • Vol. 54, Issue 1 (Obituaries, News \& Commentaries, Community Reports)

\title{
Fred T. Haddock
}

Nicole Casal Moore ${ }^{1}$

${ }^{1}$ University of Michigan

Published on: Mar 01, 2022

DOI: $10.3847 / 25 c 2 c f e b .6 f c a d c 95$

License: Creative Commons Attribution 4.0 International License (CC-BY 4.0). 
Frederick Haddock, an astronomy professor and former director of the University of Michigan's Radio Astronomy Observatory, died of lung cancer on Friday, February 20, 2009 at his home in Ann Arbor, Michigan. He was 89.

Haddock was born in Independence, Missouri, in 1919. He spent his childhood and teen years in Tulsa, Oklahoma. He studied physics and electrical engineering and became a nationally ranked wrestler at Massachusetts Institute of Technology, graduating with high honors in 1941.

Recruited to work at the Naval Research Lab in Washington, D.C., Haddock was credited with helping to shorten the war in the Pacific. He led a team of scientists and engineers who pioneered the first radar antenna used inside a submarine periscope, and many Japanese ships were sunk with its aid. After the war, Haddock gained fame as one of the pioneers of radio astronomy. He discovered radio bursts from solar flares at centimeter wavelengths and was the first to detect thermal radio emissions from the Orion Nebula, as well as other galactic and extragalactic regions and objects.

He received a tenured professorship at the University of Michigan (U-M) and moved to Ann Arbor with his family in 1956. He designed and managed the construction of the UM 85-foot radio telescope at Peach Mountain, which was instrumental throughout the '60s and '70s in the discovery and investigation of pulsars, quasars and black holes, and is still in use today. In addition to being the director of the Radio Astronomy Observatory from 1961-84, Haddock also taught classes at U-M in electrical engineering and at its Residential College.

Considered by friends and colleagues to be one of the first true rocket scientists, Haddock served on numerous NASA and Goddard Space Flight Center advisory committees and panels, as well as publishing more than 62 papers, many articles and book chapters. He was the principal investigator for the Journeyman Rocket Experiments I and II and the Orbiting Geophysical Observatories I-V, from 1959-67. He was part of the Ad Hoc Working Group for the Apollo Scientific Experiments and Training and Manned Orbiting Laboratory Astronomy Panel. Haddock also worked with NASA from 1970-86 as principal investigator for Interplanetary Probe I and coinvestigator for Voyager I and II projects. Haddock lectured as a visiting professor at Caltech; University of Manchester, England; Raman Institute, India; and was a regular 
delegate of the International Astronomical Union. He received several honorary doctorates.

Haddock's personal interests included in-depth studies of psychology, the history of science, modern architecture and sports cars. An avid reader, his library boasts more than 4,000 books. Haddock was an honorary member of the Huron Valley Chapter of the American Institute of Architects, and he owned the Frank Lloyd Wright-designed Haddock-Whiteford House.

He is survived by his wife, Deborah Fredericks; sons Thomas and Richard; and grandchildren Irene, Tommy, Colleen and Chelsea.

Adapted from the original obituary with permission of The University Record, University of Michigan: https://www.ur.umich.edu/0809/Mar30 09/obits.ph p 